\title{
The Design for Product Service Supportability (DfPSSu) Methodology: Generating Sector-Specific Guidelines and Rules to Improve Product Service Systems (PSSs)
}

\author{
Claudio Sassanelli ${ }^{1,2(\mathbb{*})}$, Giuditta Pezzotta ${ }^{2}$, Roberto Sala ${ }^{2}$, \\ Angelos Koutopes ${ }^{3}$, and Sergio Terzi ${ }^{1}$ \\ ${ }^{1}$ Department of Economics, Management and Industrial Engineering, Politecnico di Milano, \\ Via R. Lambruschini 4/b, 20156 Milan, Italy \\ \{claudio.sassanelli, sergio.terzi\}@polimi.it \\ 2 Department of Management, Information and Production Engineering, University of Bergamo, \\ Viale Marconi, 5, 24044 Dalmine, BG, Italy \\ \{claudio.sassanelli, giuditta.pezzotta, roberto.sala\}@unibg.it \\ ${ }^{3}$ N. Bazigos S.A. Design and Manufacturing of Moulds, \\ 26th Km Old National Road - Athens - Thiva, 19600 Mandra, Attikis, Greece \\ akoutoupes@bazigosmolds.com
}

\begin{abstract}
Nowadays manufacturers' need to systematically develop innovative integrated solutions is increasingly pushed by new technologies, a multiple functionalities demand and a change in the customer value perception. For these reasons, it is very complex for Product Service Systems (PSS) providers to fulfil all the design requirements: designers must consider all the objectives the PSS wants to achieve during its whole lifecycle according to different criteria, which are often to be considered according to a trade-off balance. At present, Design for $\mathrm{X}$ (DfX) design methods represent the most important attempt to enhance product development according to certain characteristics or lifecycle phases: authors believe they can also support the PSS design, redesigning or enhancing products in certain X-dimensions, in particular those ones related to "service supportability". On this basis, a methodology generating new Design for X (DfX) guidelines has been proposed: in this paper an application case in the mold industry shows how a physical product can be improved when a service has to be added and integrated. At the same time, new industry-specific PSS design guidelines and rules are proposed.
\end{abstract}

Keywords: Product Service System (PSS) · PSS design · Design for X (DfX) Design for Product Service Supportability (DfPSSu) · Design guideline 


\section{Introduction}

Nowadays manufacturers are always more absorbed by Service Economy. To boost their performance the paradigm of Product-Service System (PSS) has been presented to the market. PSSs are characterized by the integration of Products and Services bundled into unique solutions fulfilling the user's needs [1]. However, companies are not fully actually aided by consistent PSS design methodologies, and supporting tools, which could enable them to focus on both customer's perspective and company's internal performance but also to integrate service and product components along their whole lifecycle [2]. Some traditional PSS methodologies (e.g. [3-5]) tried to continue going down the river of traditional product design approaches to attempt to fill this gap. Moreover, [6] proposed some more conceptual strategies to move in that direction: the idea was that starting from the physical product properties and features, service design can be properly integrated in it, without neglecting a lifecycle perspective on the entire integrated solution. In such a competitive and fast changing environment, concurrent engineering approaches, such as Design for X (DfX), have been proposed in literature, being more able to cope with different simultaneous issues dealing with products, processes and systems design. Overcoming the typical issues of the traditional sequential engineering, this kind of approaches can indeed adapt the physical products in various ways according to the PSS lifecycle, also addressing designers' lack of knowledge in important product and service lifecycle areas [7]. A methodology generating Design Guidelines and Rules, fostering the adoption of the Design for Product Service Supportability (DfPSSu) approach [8], aims at integrating product and services with a lifecycle view. With this objective, Sect. 2 describes the research methodology adopted and Sect. 3 the application case characteristics. Finally, Sect. 4 presents the validation results and Sect. 5 introduces the future research developments.

\section{The Methodology for Generating DfPSSu Guidelines/Rules}

Figure 1 summarizes the methodology mentioned above: it has the aim of creating Design Guidelines and Rules to enhance the design of the product features enabling and supporting the delivery of excellent services. Guidelines provide a proper basis for considering generic, non-company-specific, lifecycle oriented information to be followed during the design phases. Rules become concrete and quantitative instructions for PSS developers to be followed during their daily specific design activities, representing the characterizing knowledge belonging to the company. The methodology, and its supporting tool to manage the generated Guidelines and Rules in a consistent repository, have been developed according to different research traditions [9]. The methodology is composed of 6 phases clustered in 4 main sections. 


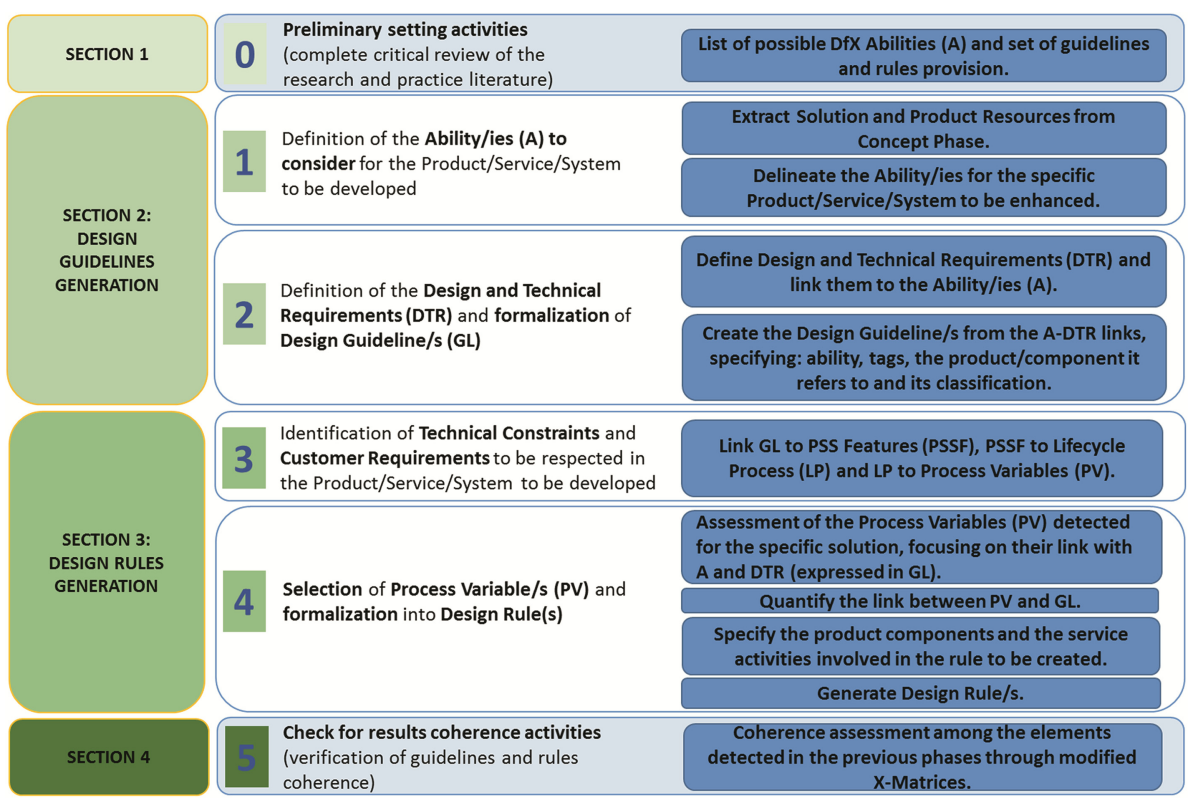

Fig. 1. The PSS design guideline/rule methodology (adapted by [9])

Section 1: before starting with the content guideline and rule creation procedure, preliminary activities need to be performed in order to collect the basic information to be used through the adoption of the methodology. All the Design for X approaches that could be involved during the PSS design are collected: they represent the possible Abilities (A) the PSS under design could achieve and represent the starting point for the guidelines/rules definition. The DfX Ability concept is based on the "function" concept defined by [10]: they are those principles through which the PSS functions can be explicated and explained and represents what exactly the guideline addresses.

Section 2: The design process can start when a PSS concept is already available. Once defined in Phase 1 the Ability/ies (A) the product under design has to achieve, an analysis must be conducted in order to create, if not existing, new suitable content guideline/s. Thus, Design and Technical Requirements (DTR) are defined: they represent the practical and technical recommendations to be followed by designers and engineers, through which abilities could be achieved. Therefore, the new DTR has to be linked to the Ability/ies, also specifying the importance degree of the relationships. Based on the identified links between A and DTR, guidelines able to guide the designer/ engineer activities in the Product/Service/System development must be formalized in text and made available as company knowledge.

Section 3: in this section design rules are created. Here, the methodology must lead the designer/engineer to focus on the specific company context. In order to create a bridge between the functionalities of the PSS to be achieved and the related lifecycle variables that need to be managed, an extended version of the Function Transformation Matrices (FTM) methodology [10] is used. A series of them, all based on the same 
structure, is adopted to document and gauge the relationships among various factors such as: (a) PSS Features (PSSF), those characteristics of the PSS components to be considered to act on DTR expressed in the Guidelines (GL); (b) PSS Lifecycle Processes (LP) represent all those activities of the PSS lifecycle (from the design to disposal phase); (c) PSS Process Variables (PV) are those variables which need to be detected since they affect LP. They can belong to any process of the several phases composing the PSS lifecycle. Finally, Design Rules are systematically developed based on the links found in the previous steps: their aim is the ability-driven control of lifecycle variables in order to better manage the design activities to improve the physical product of a PSS. Design Rules are indeed developed to provide the links for controlling the variables that directly affect the PSS Ability/ies enabled by the introduction of a new service on a physical product.

Section 4: In this last section, the coherence of all the elements considered during the design process is verified, supporting designers and engineers in finding the right connections between the obtained high level Guidelines and the more operative Rules. For this aim, two modified X-Matrices [11] are used.

\section{Research Methodology and Application Case}

\subsection{Research Methodology}

The application case has been conducted with the aim of testing the suitability of the presented methodology generating DfPSSu Guidelines and Rules. The paper also evidences the related benefits for companies and the increased efficiency, deriving from its application, in solving issues in the detailed design phase of PSS. The application case was conducted in two steps. First of all, a video has been shared with participants to train them about the methodology. Thus, the face-to-face workshop has been organized to apply the methodology in the industrial context. This interactive session was led by two academics and involved two additional academics with which the company has long term relationship, in addition to the production monitoring employee and one product designer. After realizing the actual DfX methods level of use in the company, DfPSSu approach was presented. Hence, a solution, the mold digital history of repairs, has been detected through a concept design brainstorming, in order to enhance the company business. The methodology has been performed and design guidelines and rules supporting the design of this new PSS were obtained. Moreover, useful feedbacks on the suitability of the approach were given.

\subsection{The Application Case: N. BAZIGOS SA}

The application case has been conducted in N. BAZIGOS SA, a B2B Greek company designing and manufacturing molds. Design methodologies for the product itself are long established using PLM, CAD and other software tools and methods, supported by a strong and experienced design and engineering division. Going through the servitization process, their actual intent is to: reduce their environmental impact, wastes in material, energy consumption, design and machining time, time to market, frequency of 
failure; improve customer involvement in the design and customer satisfaction; increase competitiveness and income; access to new market sectors. Indeed, in the company, PSS offerings are in early stages of adoption. The provided services are offered in isolation from the product, which is the mold, without considering a combined PSS eco-system. However, the nature of this manufacturing sector dictated up to now that the services aspect is indirectly treated. Given this lack of service-oriented approaches in the industry, the company is thus considering new PSS projects like mold delivery time estimation as a service, maintenance history per customer, joint provider-customer proactive production planning for mold modifications or opinion mining offered to customers as a service. This would enhance the monitoring and control of mold lifecycle and shorten mold downtime.

The methodology was applied in N. BAZIGOS SA, starting with Sect. 1, where some preliminary setting activities consisted in assessing the AS-IS of its design procedures. The company does not adopt a really structured approach to design mold. They follow some basic principles, e.g. optimize mold cycle time (to inject, cool and eject a part). Moreover, the design guidelines and rules, that represents the company knowhow needed to implement these approaches, are not codified and written down and reside only in designers' background. Furthermore, customers' requirements are almost connected to production optimization, from either a quantity or quality point of view. Therefore, designers are committed to add on the basic mold some extras and to focus on certain precise aspects of the product lifecycle in a concurrent way. Most of the time the main target for the design team is to optimize, also through a consistent choice of the steel adopted, the expected number of pieces produced with the mold, minimizing downtimes. Thus, when steel hardening can be avoided, the company costs are lower, the price for the customer is lower but it will soon present more problems in maintenance. To manage this issue, principles belonging to Design for Modularity and Customizability, adding changeable cups and bases, are directly linked to Maintainability. On the contrary, using thicker plates or considering other suitable solutions, the mold can become more reliable. However, it requires a more complex design and principles as Maintainability cannot be neglected. Therefore, through the DfPSSu Methodology, it is useful to reconsider the design of an already existing mold in order to improve its functionalities (especially from a Maintainability point of view) and understand what would change. A new solution, able to meet N. BAZIGOS SA's needs, was identified: the digital history of repairs of the mold. Thus, a product to be redesigned, referring to a customer operating in the plastic industry, was detected: a " 2 cavity, 1 L Seal Lid" mold. The description of the main components (shown in Fig. 2) and the main issues with them are shown in Table 1: 

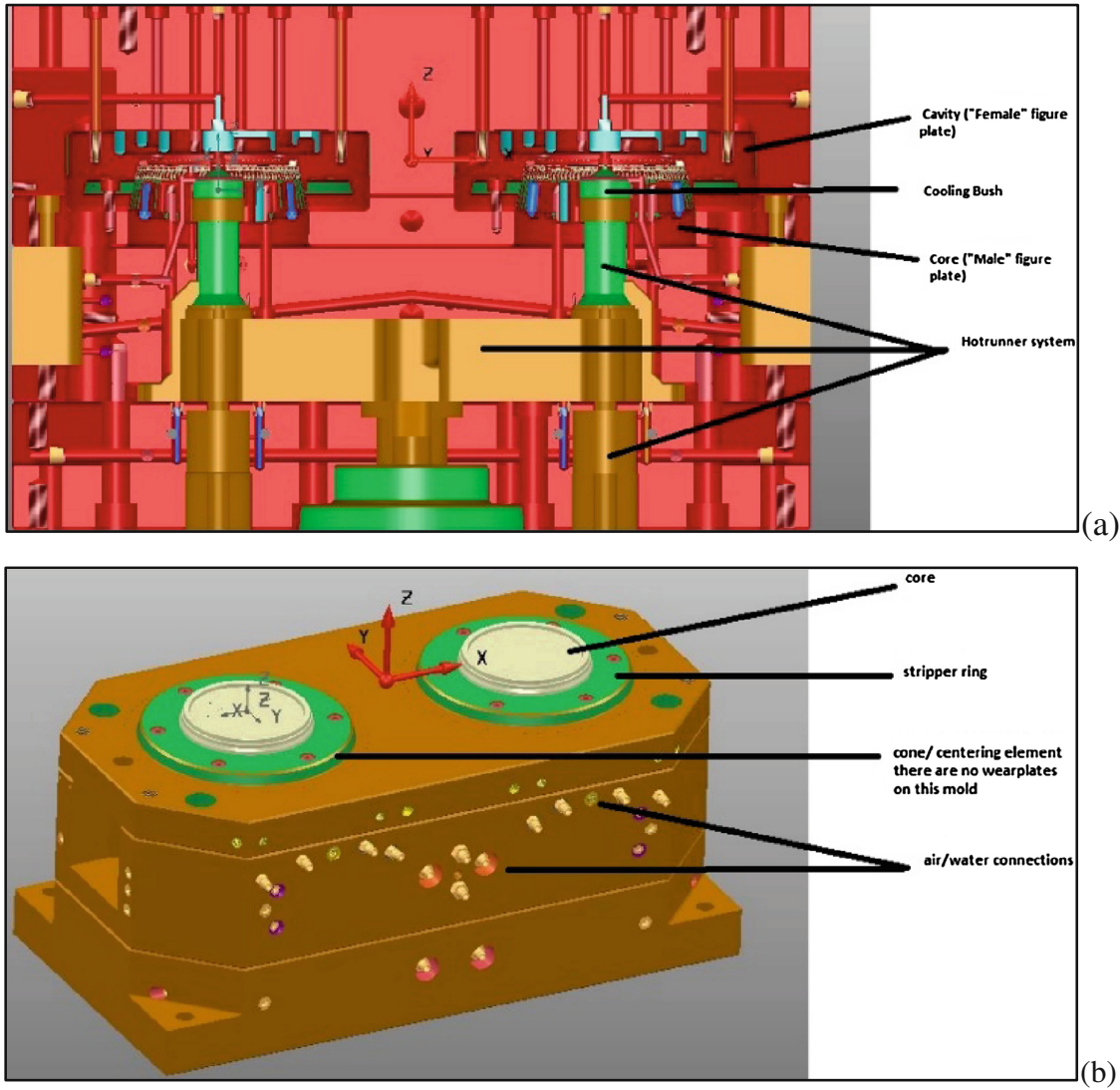

Fig. 2. " 2 cavity, 1 L Seal Lid" mold: General section (a) and fixed side (b)

Table 1. " 2 cavity, 1 L Seal Lid" mold: component and issues description

\begin{tabular}{l|l|l}
\hline Component & Description & Issue \\
\hline 1. Core \& Cavity & $\begin{array}{l}\text { The two halves of the mold that create } \\
\text { the plastic product geometry }\end{array}$ & $\begin{array}{l}\text { They usually carry the centering } \\
\text { elements: these are the two parts that } \\
\text { need to be aligned properly }\end{array}$ \\
\hline 2. Cooling bush & $\begin{array}{l}\text { An insert, that carries the injection } \\
\text { point (hole) from which the plastic } \\
\text { flows, also carries cooling circuit) }\end{array}$ & $\begin{array}{l}\text { The hole is damaged by material } \\
\text { flow. They are designed as inserts for } \\
\text { manufacturability reason, and thus } \\
\text { they are also replaceable }\end{array}$ \\
\hline 3. Hotrunner & $\begin{array}{l}\text { Provided by specialized suppliers, } \\
\text { distributes the plastic material to } \\
\text { multiple cavities }\end{array}$ & $\begin{array}{l}\text { Nozzle tips (and other contact points } \\
\text { with accurate fitting are often } \\
\text { damaged by material flow }\end{array}$ \\
\hline 4. Stripper ring & $\begin{array}{l}\text { The component that moves relatively } \\
\text { to the core, in order to eject the plastic } \\
\text { part from the mold) }\end{array}$ & $\begin{array}{l}\text { Accurate fitting is required and, due } \\
\text { to natural wear, it needs repair or } \\
\text { replacement }\end{array}$ \\
\hline
\end{tabular}




\subsection{Guidelines and Rules Generation in N. BAZIGOS SA}

Having analyzed the current design approach of the company, according to the methodology procedure in Sect. 1, and detected the solution to be developed, DfPSSu Guidelines and Rules were developed following the steps described from Sects. 2, 3 and 4. Besides the aim of guiding the creation of a product consistent with the customer's needs, the Design Guidelines and Rules are useful to limit the reworks, since they are thought to give precise information on how to design the product.

Figure 3 (from solutions in the bottom part of the figure following a clockwise direction) summarizes the results obtained through the application of Sect. 2: it begins with Phase 1, focused on Abilities definition, the five most important abilities to develop the solution desired have been identified. They were related to the physical product properties needed for the PSS provision: Modularity, Maintainability, Inspectability, Easy Assembly/Disassembly operations, ID Coding \& Traceability.

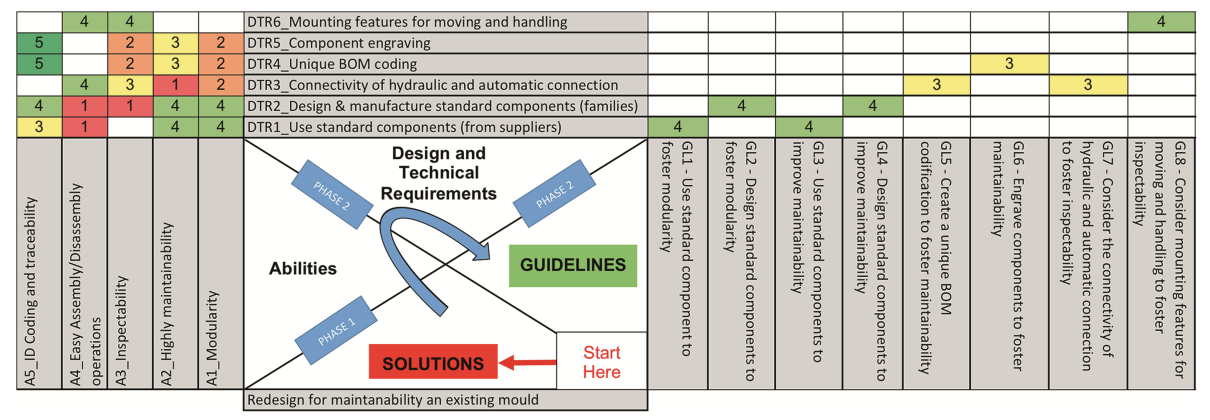

Fig. 3. A section of the FTM - X Matrix from solution to guidelines

In Phase 2, six DTRs were defined to fulfill the previous Abilities: use standard components from suppliers, design and manufacture standard components for product families, connectivity of hydraulic and automatic connection, unique BOM coding, component engraving, mounting features for moving and handling. Then, the relationship grade between each Ability and DTR was defined. As a result, fourteen Guidelines (GL) were obtained since only the relationships with a weight equal or higher than " 3 " were considered significant and thus investigated and translated in operational guideline for the designer.

Later, Sect. 3, summarized in Fig. 4 (from guidelines in the bottom part of the figure following a clockwise direction), was carried out in order to create detailed rules. In Phase 3 the PSS Feature were defined. They were aimed at improving the Abilities, defined in the previous steps, of some critical components, such as: hotrunner, guiding components, cooling bush, sockets, centering elements, water manifold, mounting holes, centering cone. Then, the team brainstormed once again to define the relationship between the Guidelines and the PSSF. In Phase 4, the designers' attention moved on the Lifecycle Process (LP) steps identification, in particular seven phases were identified (Concept \& Design, Manufacturing, Assembly, Validation, Use, Maintenance, Disposal). The definition of the relationships between the PSSF and the LP, aided 
engineers in understanding the value of the PSSF in all the phases of the solution lifecycle. Once again, the resulting links fostered the creation of the Design Rules to be followed by the designers. 53 specific new Rules have been created (listed in part in Fig. 4).

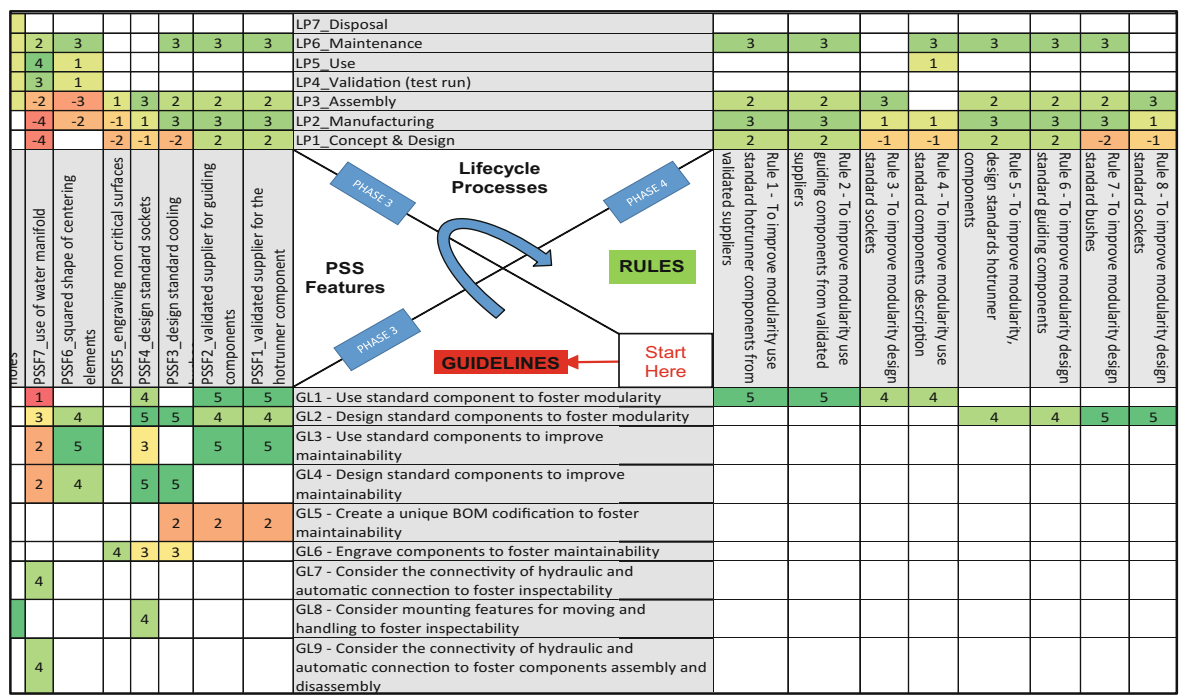

Fig. 4. A section of the FTM - X Matrix from guidelines to rules

Finally, in Phase 5, the team checked the coherence between all the information created along the methodology thanks to the analysis of the X-Matrices. No strong contradictions emerged. Only one Guideline (GL5), not being linked to any PSSF, wasn't explicated in specific Rules. Moreover, Rules related to PSSF6 (squared shape of centering element) and PSSF7 (use of water manifold) were characterized by a very negative weight at the beginning of PSS lifecycle, resulting in the need of a strong effort for the company: designers should consider, with a further trade-off brainstorming, if it's worth to follow them. However, many benefits could be obtained also by their achievement. For example, in order to achieve A3, Inspectability, DTR3, Connectivity of hydraulic and automatic connection, and DTR6, Mounting features for moving and handling, were considered. In particular, the relation A3-DTR3 was explicated in GL7 ("Consider the connectivity of hydraulic and automatic connection to foster inspectability"). To act on this, PSSF7, Use of water manifold, was considered: this feature requires a very important effort in the beginning of the PSS lifecycle (Concept \& Design and Manufacturing and less in Assembly) but makes the validation test run easier, giving also a huge improvement in the Use and Maintenance phases. Indeed, Rule 30, "To improve Inspectability, use water manifold while designing the connectivity of hydraulic and automatic connection", contributes to GL7's aim. 


\section{Discussion}

Several and different results have been obtained through this application case. The main evidence is that the proposed methodology is able to solve product engineering issues, fostering the product and service features integration in the detailed PSS design [9]. In particular, following the methodology, 14 new Guidelines (Fig. 3) and 53 connected Rules (Fig. 4) were obtained and checked. Feedbacks collected during the methodology application in N. BAZIGOS SA could be considered as an additional result: the difference between "Guidelines" and "Rules" could be strengthened through the way they are written (e.g. considering the use of the passive tense for the Guidelines) and the X-Matrix visualization could be enhanced (to automatically better explain its outcomes). Their main concern with the methodology regarded the effort needed to apply it, if compared to their standard procedures. N. BAZIGOS SA is a SME: designers are free to design as they want, always keeping in mind the mold manufacturability but without the need of always designing something really innovative. The mold, a B2B industrial product, should only satisfy the customer's requirements: its innovation could be considered strategic only from the service point of view, confirming the importance of the DfPSSu concept. Indeed the methodology adoption would require designers an additional amount of time to get used to the different concepts introduced (even if it resulted to be very easy to follow) and to structure the obtained knowledge in the tool repository. In companies it is difficult to change routines and to work with a new tool: experienced designers could state they don't need to use the proposed methodology because they already know the design rules. Finally, the methodology appeared to be pretty much useful to capture brainstorming during the design phase but at the same moment it represents a very structured way to govern it, decreasing a bit the sense of relax supposed to obtain new ideas. However, according to N. BAZIGOS SA employees, this methodology can improve in an important way the PSS design phase mainly if applied in big multinational companies. Big companies indeed typically are more involved in the continuous process of innovation of their solutions, follow very strict requirements and have a stronger structure of resources able to exploit this procedure in a deeper way. Furthermore, with its adoption, the problem-solving process could be simplified and speeded up also along the space, in different industrial plants scattered in diverse places, and the time, among different designers generations, and can foster collaboration among companies' divisions and networks.

\section{Conclusions and Further Developments}

This paper investigates how to support companies in the integration of service features already in the product design of the PSS. In order to do it and to have an empirical feedback in the industrial context, the methodology generating DfPSSu guidelines and rules proposed in [9] has been adopted in an application case. This has been thus conducted in a SME producing mold for B2B market, willing to go through servitization. Thus, among the already existing products belonging to the company portfolio, the solution to be designed and provided to the customer as a PSS has been hence detected: 
the injection mold (for plastic industry) maintenance, based on the digital history of repairs. Through this application case, the physical product was enhanced and service features were integrated in it: indeed the methodology confirmed to be strongly engineering based, being aimed at the development of a new DfX-driven approach for PSS development and at easing the problem solving process, typical of the design phase, also balancing in a trade-off the different abilities to be satisfied. The case was conducted allowing designers/engineers to freely use the methodology. According to them, the proposed methodology would yield more benefits to a large company, where designers might be based even in different countries - but required to maintain consistency in their designs. In smaller companies, where experienced designers train junior designers, day by day - working next to each other - knowledge, although valuable, remains tacit. Based on this, a further test could be conducted in future in a multinational company in order to evaluate the design methodology effectiveness not only in SMEs but also in such a different context. Finally, new sector-specific DfPSSu Guidelines and Rules were obtained: in this sense, the provision of a tool, used as a repository for both the generic Guidelines and the more specific Rules, can ease designers' activities in protocolling the design knowledge obtained during the design phase. This knowledge can be linked, through the use of tags, either to the design project or to PSS Abilities or to other kind of concepts. Furthermore, this knowledge, consistently filtered, can also be reused for future design projects. Based on this, a tool, already used in the application case in its prototype version, is going to be developed and provided to practitioners.

Acknowledgments. This work was funded by the European Commission through Diversity Project, GA 636692, under the H2020 program.

\section{References}

1. Goedkoop, M., Van Halen, C.J.G., te Riele, H.R.M., Rommens, P.J.M.: Product Service systems, Ecological and Economic Basics, vol. 36, March 1999

2. Pezzotta, G., Pirola, F., Rondini, A., Pinto, R., Ouertani, M.-Z.: Towards a methodology to engineer industrial product-service system - evidence from power and automation industry. CIRP J. Manuf. Sci. Technol. 15, 19-32 (2016)

3. Aurich, C., Fuchs, C., Wagenknecht, C.: Modular design of technical product-service systems. In: Brissaud, D., Tichkiewitch, S., Zwolinski, P. (eds.) Innovation in Life Cycle Engineering and Sustainable Development, pp. 303-320. Springer, Dordrecht (2006). https:// doi.org/10.1007/1-4020-4617-0_21

4. Maussang, N., Zwolinski, P., Brissaud, D.: Product-service system design methodology: from the PSS architecture design to the products specifications. J. Eng. Des. 20(4), 349-366 (2009)

5. Hara, T., Arai, T., Shimomura, Y., Sakao, T.: Service CAD system to integrate product and human activity for total value. CIRP J. Manuf. Sci. Technol. 1(4), 262-271 (2009)

6. Tan, A.R., Matzen, D., McAloone, T.C., Evans, S.: Strategies for designing and developing services for manufacturing firms. CIRP J. Manuf. Sci. Technol. 3(2), 90-97 (2010)

7. Sundin, E.: Life-cycle perspectives of product/service-systems: in design theory. In: Sakao, T., Lindahl, M. (eds.) Introduction to Product/Service-System Design, pp. 31-49. Springer, London (2009). https://doi.org/10.1007/978-1-84882-909-1_2 
8. C. Sassanelli, G. Pezzotta, F. Pirola, S. Terzi, M. Rossi: Design for Product Service Supportability (DfPSS) approach: a state of the art to foster Product Service System (PSS) design. In: 8th CIRP IPSS 2016, vol. 47, pp. 192-197 (2016)

9. Sassanelli, C., Pezzotta, G., Sala, R., Correia, A., Terzi, S.: Testing the methodology to generate Design for Product Service Supportability (DfPSS) guidelines and rules: an application case. In: Procedia CIRP, pp. 265-270 (2017)

10. Mital, A., Desai, A., Subramanian, A., Mital, A.: Product Development. Elsevier (2008)

11. Jackson, T.L.: Hoshin Kanri for the Lean Enterprise: Developing Competitive Capabilities and Managing Profit (2006) 